\title{
SCIMPI: a new borehole observatory
}

\author{
T. Lado-Insua ${ }^{1, *}$, K. Moran ${ }^{1,2,3}$, I. Kulin ${ }^{2,3}$, S. Farrington ${ }^{4}$, and J. B. Newman ${ }^{1,5}$ \\ ${ }^{1}$ Department of Ocean Engineering, University of Rhode Island, Bay Campus, Narragansett, RI 02882, USA \\ ${ }^{2}$ Graduate School of Oceanography, University of Rhode Island, Bay Campus, Narragansett, RI 02882, USA \\ ${ }^{3}$ Ocean Networks Canada, University of Victoria, P.O. Box 1700 STN CSC, Victoria, BC V8W 2Y2, Canada \\ ${ }^{4}$ Transcend Engineering and Technology, LLC, P.O. Box 222, Gaysville, VT 05746, USA \\ ${ }^{5}$ Woods Hole Marine Systems Inc., P.O. Box 164, Woods Hole, MA 02543, USA \\ *currently at: Graduate School of Oceanography, University of Rhode Island, Bay Campus, \\ Narragansett, RI 02882, USA
}

Correspondence to: T. Lado-Insua (ladoinsuat@egr.uri.edu)

Received: 16 July 2013 - Revised: 23 September 2013 - Accepted: 26 September 2013 - Published: 5 November 2013

\begin{abstract}
The Simple Cabled Instrument for Measuring Parameters in-situ (SCIMPI) is a new borehole observatory instrument designed to study dynamic processes below the seafloor. SCIMPI performs time series measurements of temperature, pressure and electrical resistivity at a series of depths, tailored for site-specific scientific objectives. SCIMPI's modular design enables tailoring of the type, depth distribution, and frequency of measurements based on the study goals and sediment characteristics. The first prototype is designed for $300 \mathrm{~m}$ below the seafloor in soft sediment and $1500 \mathrm{~m}$ b.s.l. However, SCIMPI could be tailored for deeper goals. The instrument can be configured for autonomous or cabled observatory deployments and has successfully undergone a number of tests, including pressure, communications, battery life, and interfacing with other drill-ship equipment. Here we discuss the design of the instrument, its capabilities, and the testing process it has passed through during four years of development. SCIMPI was successfully deployed on the Cascadia margin within the NEPTUNE Canada observatory network during IODP Expedition 341S in May 2013.
\end{abstract}

\section{Introduction}

A full understanding of earth system science requires the study of elemental (e.g., carbon and nitrogen) and heat fluxes across the seafloor-ocean boundary. Polar areas are currently responding the greatest to global warming and are of special interest for answering scientific questions about the processes of destabilization of permafrost and hydrates, which may accelerate the release of methane into the ocean and potentially the atmosphere. The amount of methane released from warming and its impact as a positive feedback in climate change remain undetermined. Methane reservoirs are also ubiquitous in other areas of the deep ocean in hydrate form and are an important, little-known component of the carbon cycle whose effect on global warming as greenhouse gases is a major component of this problem (Kvenvolden, 1995; Beerling et al., 2009).
SCIMPI (Fig. 1) is a borehole observatory instrument for placement in unconsolidated sediments. It will operate for two to four years on internal batteries that can be replenished via remotely operated vehicle (ROV) providing high spatio-temporal resolution measurements of the physical properties in the sediment, or connected to a cabled observatory system for real-time data acquisition. With either periodic battery replacement or connection to a cabled observatory, SCIMPI provides long-term observations for understanding sub-seafloor dynamics such as changes in seafloor and sub-seafloor gas hydrate systems. The main advantages of SCIMPI are its configurability, comparatively low equipment cost, and simple operational requirements, making it an economical and versatile system for scientific research. 


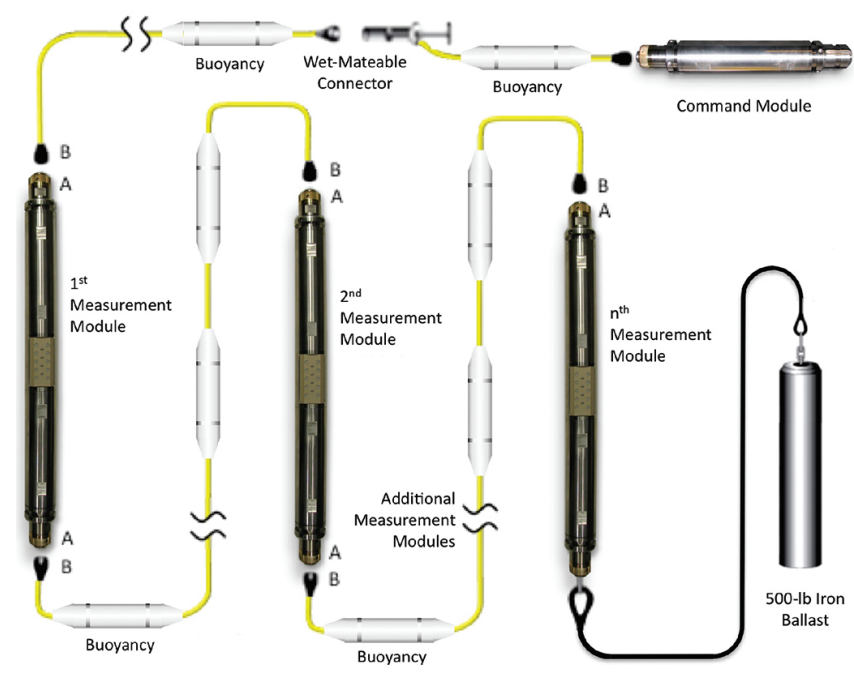

Figure 1. SCIMPI schematic showing the modules connected to each other to form a single string that was deployed in an open borehole to depths up to $300 \mathrm{~m}$ b.s.f.

\section{System configuration and specifications}

SCIMPI is designed for dynamic geotechnical conditions in which the borehole closes in on the device once the drill string through which it is emplaced is withdrawn. Borehole relaxation occurs because of two different processes: slower, creep-dominated deformation in fine-grained clays and shales, and immediate collapse in uncemented coarsedominated sediments.

A SCIMPI string consists of multiple measurement modules and a command module connected by varying lengths of cable, with a ballast weight at the bottom of the string and flotation distributed along the string to keep the cable taut during deployment. It is powered and controlled via an underwater-mateable connection to either a ROV-replaceable command module or cabled observatory infrastructure. The modules and cable segments are physically daisy-chained while power and communications are on a multi-drop bus, a combination that provides several benefits. Each SCIMPI module is composed of interchangeable housing components that, with cables of varying length, allow any combination and distribution of sensors to be formed. Sensors currently included in SCIMPI modules are the Seabird Electronics SBE-38 precision oceanographic thermometer and the Paroscientific Digiquartz series 4000 pressure sensor, both commonly used in ocean sciences to characterize sub-seabed environments having dynamic fluid flow. Resistivity is measured by an Electrical Resistivity Smart Sensor (ERSS) from Transcend Engineering and Technology which acquires measurements from any Wenner-style (e.g., galvanically coupled, 4-electrode, Wenner, 1916) resistivity array. SCIMPI measurement modules each incorporate a Wenner-style array for measuring electrical resistivity of borehole sediments. The
ERSS configuration can be tailored to the specific requirements of the deployment with the SCIMPI default set for a range of $0.1-100 \Omega \mathrm{m}$ using bi-polar excitation at $100 \mathrm{~Hz}$. The ERSS does not correct internally for ambient temperature, as thermal effects are media dependent and should be considered in relation to the deployment medium during data analysis. All SCIMPI sensors are factory calibrated by their manufacturers. Additional 5 to 15 VDC sensors that communicate via RS-485 can be added without requiring software or circuit modifications.

Other benefits of the design are efficient power management and flexible communications. Each measurement module contains a Texas Instruments MSP430-based processor responsible for powering and communicating with up to four sensors on an internal two-wire RS-485 bus (Fig. 2). Each sensor's power is isolated and individually switchable. A low voltage signal from the command module activates all measurement modules when needed, causing them to latch on to the external power bus, boot up, and await instructions.

Inactive measurement modules consume a few microwatts of power. Active modules respond to a Modbus RTUcompliant protocol over an external two-wire RS-485 bus that connects all modules. The protocol encapsulates each sensor's command set, so software revisions are not necessary to support new sensors. Power is supplied to all modules via a two-wire bus that allows battery packs to be distributed anywhere in the SCIMPI system string. Internal battery packs deliver $16500 \mathrm{mAh}$ at $14 \mathrm{~V}$ using primary lithium-thionyl chloride cells. Distributing the battery power throughout the modules limits the required module size to allow a complete autonomous SCIMPI to be deployed through the drill pipe without needing an ROV. Back-charging is prevented so that power initially provided by modules down in the borehole can be replaced by power from a module containing fresh batteries at the seafloor.

The command module, which remains above the seafloor, contains power conversion and seawater isolation circuitry, a programmable datalogger, and can be extended to hold additional battery packs. The datalogger is a single-board computer (SBC) based on an ARM9 processor running Microsoft's dot-NET Micro Framework. To conserve power, the SBC is supervised by a TI MSP-430 microcontroller that includes a real-time clock, keeps track of the datalogger's status, and powers up the dot-NET system to acquire data according to the user-defined schedule. The system records data to $\log$ files in ASCII format with UTC time stamps on a 32-GB SD memory card.

SCIMPI is configured via a Windows application, "SCIMPI Config", provided by Transcend Engineering and Technology. The program enables the user to specify sensor commands, sequences of sensor power switching and polling, and the overall polling interval. The command module automatically switches between different operational modes depending on the status of its "up-hole" and "downhole" ends. Cabled mode is automatically entered whenever 


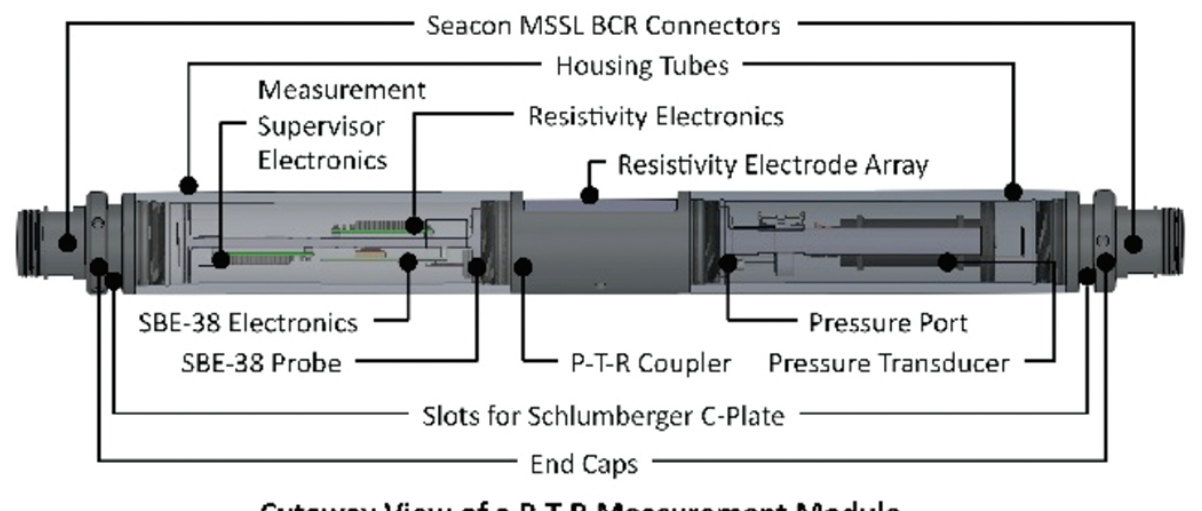

Cutaway View of a P-T-R Measurement Module

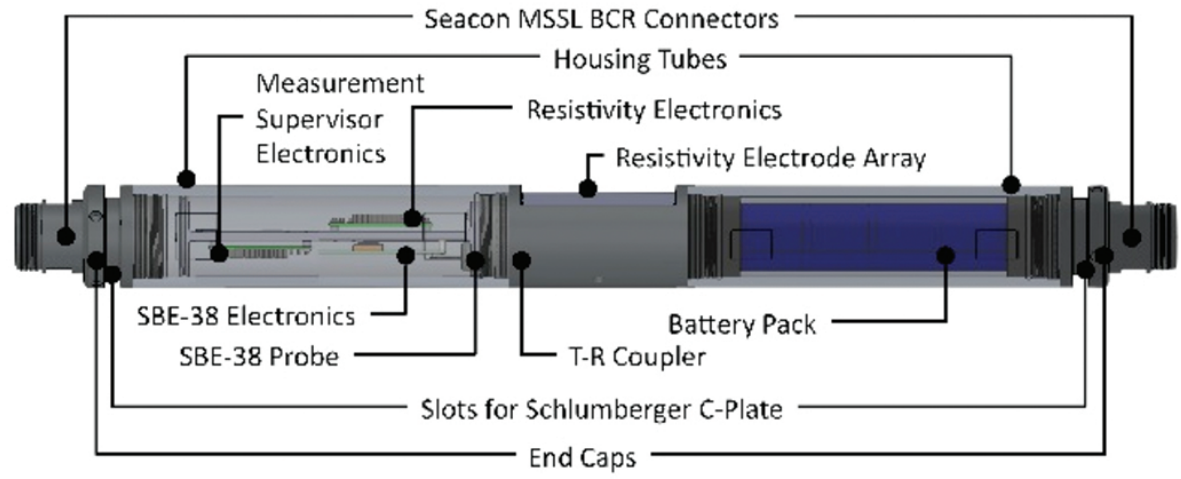

Cutaway View of a T-R-B Measurement Module

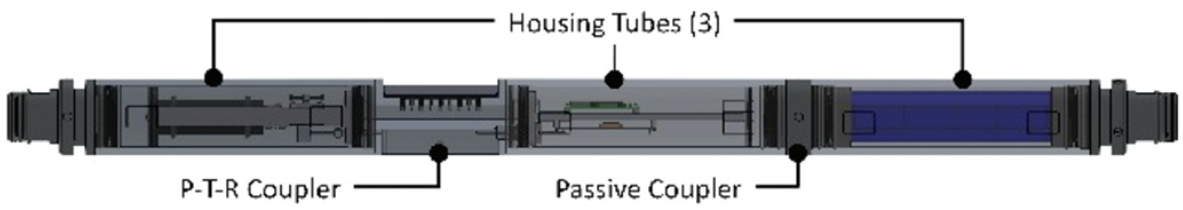

3-Chamber P-T-R-B Measurement Module

Figure 2. Cutaway view of: PTR (pressure-temperature-resistivity) measurement module (above), TRB (temperature-resistivity-batteries) measurement module (center) and PTRB (pressure-temperature-resistivity-batteries) measurement module (below).

power ( 9 to $80 \mathrm{VDC}$ ) is applied to the up-hole end, such as through a wireline umbilical or cabled network. In $c a$ bled mode, SCIMPI acquires measurements continually and writes time-stamped ASCII data to the up-hole RS-485 bus in addition to the internal SD memory card. When up-hole power is removed, SCIMPI enters autonomous mode. In this mode, the command module electrically isolates the up-hole connector to avoid any connection with seawater, and enters an ultra-low-power sleep mode that is interrupted at a user-specified interval to acquire and record measurements. SCIMPI will be lowered into its borehole in cabled mode while powered via the drill-ship's wireline cable. Upon release, it will automatically switch to autonomous mode powered by the internal batteries. If connected via ROV to cabled observatory power, SCIMPI will again enter cabled mode and produce data continually.

SCIMPI is designed for a water depth of $6000 \mathrm{~m}$ b.s.l. and a sediment depth up to $\sim 1200 \mathrm{mb}$.s.l. Although the first SCIMPI prototype is limited by its flotation material to $1500 \mathrm{~m}$ b.s.l., the flotation of the system can be adapted to different site depths. The flotation keeps the SCIMPI cable taut during installation with the underwater-mateable connector and command module accessible above the seafloor during installation. In a similar way, the depth below seafloor of the first prototype is $300 \mathrm{~m}$, but future systems could go as deep as $1200 \mathrm{~m}$ (maximum depth below seafloor based on the RS-482 communication protocol). 
Table 1. Specifications of the SCIMPI prototype.

\begin{tabular}{llll}
\hline $\begin{array}{l}\text { Temperature } \\
\text { (Modified Seabird SBE-38) }\end{array}$ & $\begin{array}{l}\text { Electrical Resistivity Smart } \\
\text { Sensor (ERSS) }\end{array}$ & $\begin{array}{l}\text { Pressure } \\
\text { (Paroscientific Model } \\
410 \mathrm{~K}-101)\end{array}$ & $\begin{array}{l}\text { Housing } \\
\text { (Standard Measurement } \\
\text { Module) }\end{array}$ \\
\hline $\begin{array}{l}\text { Range: }-5 \text { to }+35^{\circ} \mathrm{C} \\
\text { Resolution: } 0.00025^{\circ} \mathrm{C}\end{array}$ & $\begin{array}{l}\text { Range: } 0.1 \text { to } 100 \Omega \mathrm{m} \\
\text { (default reconfigurable) }\end{array}$ & $\begin{array}{l}\text { Range: 0 to } 10000 \mathrm{psi} \\
\text { (other ranges available) }\end{array}$ & $\begin{array}{l}\text { Diameter: } 76.2 \mathrm{~mm} \\
\text { Length: } 870 \mathrm{~mm} \\
\text { Weight: } 16.4 \mathrm{~kg}\end{array}$ \\
\hline $\begin{array}{l}\text { Absolute accuracy: } \pm 0.001{ }^{\circ} \mathrm{C} \\
\begin{array}{l}\text { Deployment accuracy }(3 \mathrm{yr}): \\
\pm 0.007^{\circ} \mathrm{C}\end{array}\end{array}$ & $\begin{array}{l}\text { Absolute accuracy: } \\
0.025 \Omega \mathrm{m}\end{array}$ & $\begin{array}{l}\text { Absolute accuracy: } \\
0.01 \%\end{array}$ & $\begin{array}{l}\text { Material: } 17-4 \mathrm{PH} \text { Stainless } \\
\text { Steel, condition H1025 }\end{array}$ \\
\hline $\begin{array}{l}\text { Drift: } \pm 0.001{ }^{\circ} \mathrm{C} \text { per } 6 \text { months } \\
\text { Resolution: } 0.00001 \Omega \mathrm{m}\end{array}$ & Resolution: $0.0001 \%$ & Design pressure: $8760 \mathrm{psi}$ \\
\hline
\end{tabular}

The first SCIMPI prototype is equipped to measure temperature, electrical resistivity, and pressure (Table 1). The design allows other sensors to be easily added, and we expect to incorporate other types of measurements in the future.

\section{Testing and deployment}

All SCIMPI housings were designed and pressure tested to $60 \mathrm{MPa}$ and all sensors are factory calibrated by their manufacturers and inspection tested prior to integration. The integrated system was tested both on land and at sea, with final pre-deployment testing completed in November 2011. SCIMPI was successfully deployed in the Integrated Ocean Drilling Program Site U1416 in May 2013, Expedition 341S. The R/V Thompson revisited this location on 24 June 2013 (Fig. 3). SCIMPI was specifically designed to be deployed through the drill pipe of the D/V JOIDES Resolution so no re-entry cone or casing is required. The borehole needs to be drilled to the target depth using a bit with a diameter of $9-7 / 8^{\prime \prime}$. The bit is dropped and SCIMPI is lowered down the drill string, suspending it when needed in the Schlumberger C-plate as it is fed into the drill pipe. During deployment, the multi-function telemetry module (MFTM) designed by Lamont Doherty Earth Observatory Borehole Research Group enables continuous serial communication with SCIMPI through the Schlumberger wireline cable. Once lowered to target depth in the borehole, SCIMPI is released using the electrical release system (ERS) designed and built by Stress Engineering, the wireline cable, ERS, and MFTM are retrieved, and the drill pipe is tripped out over the SCIMPI, leaving the observatory in place.

When deployed as an autonomous instrument, SCIMPI requires servicing by an ROV every two to four years to swap out the command module. If SCIMPI is connected to a network for electrical power and real-time data reporting, then an ROV is required only to complete the initial connection.

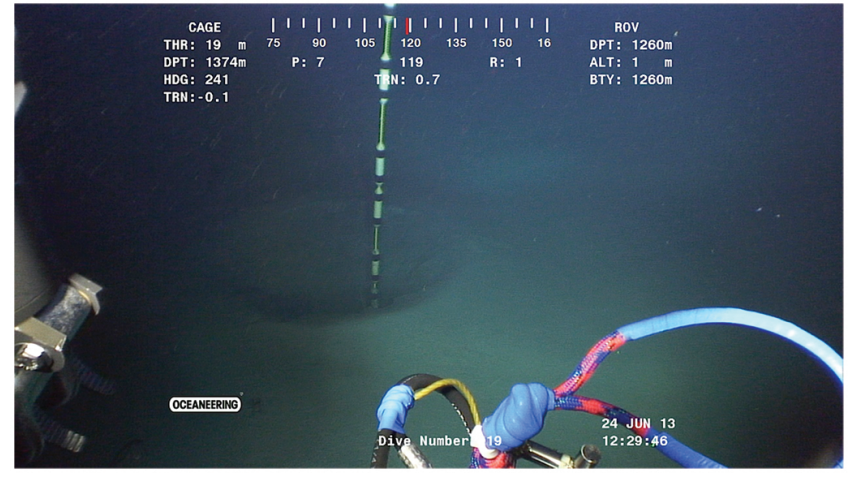

Figure 3. SCIMPI installation in the seafloor at Site U1416 as imaged with an ROV on 24 June 2013, Oceans Network Canada dive No. 19 to the Clayoquot Slope region (Image ${ }^{\circledR}$ : Ocean Networks Canada).

\section{Flexibility in the configuration}

The adjustable spacing between SCIMPI modules is one of the major advantages of the instrument. This spacing can be flexibly adjusted during a drilling expedition using core recovery and log data from the deployment site to determine optimal module positioning. To ensure this flexibility, spare cables with varying lengths will be carried on board allowing the science team to configure the instrument based on sub-seafloor characteristics determined from the interpretation of the first holes drilled. Lado-Insua et al. (2012) has developed a methodology to calculate the number and optimal distribution of modules so that long-term data from SCIMPI captures the sediment intervals with most potential for determining dynamic fluid flow processes.

For example, the formation of gas hydrates requires particular conditions of pressure and temperature. SCIMPI's sensors make it ideal for the study of gas hydrate dynamics. The stability of gas hydrates is generally assessed based on geothermal gradients (Gorman and Senger, 2010). These models could be better determined by using several SCIMPI 
installations in an area. Spatial and temporal gradients in pressure and temperature can be determined to study lateral changes in the geothermal setting. The use of SCIMPI in these environments can provide unique information on gas hydrate changes in electrical resistivity and overpressure due, for example, to processes related to changes in pore pressures. We expect SCIMPI to provide insight into the dynamics of gas hydrates in areas affected by climate change (e.g., in the Arctic where warming is amplified), fluid flow (e.g., subduction zones), and methane release (e.g., outer continental shelves and slopes).

\section{Summary}

SCIMPI is a new seafloor observatory in its final stages of development. A prototype has undergone thorough testing and was successfully deployed in May 2013. SCIMPI can measure long-term time series of temperature, pressure and electrical resistivity spatially at multiple depths below the seafloor. The instrument is highly modular and customizable to different environments, different spatial distributions of sensors, and autonomous as well as cabled operation. SCIMPI is designed for deployment into soft sediments directly through the drill string to minimize equipment and operational costs and can operate autonomously for several years on battery power.

Science applications of SCIMPI include studies of fluid flow, hydrate formation, and seismically induced pore pressure changes. The Arctic Ocean is an area particularly suited for SCIMPI deployment. Kitidis et al. (2010) demonstrated the existence of water and sediment sources of methane and nitrous oxide in the Arctic Ocean, that indicate that future sea-ice retreat may increase the flux of these gases from the sea to the atmosphere. They pointed out the importance of spatio-temporal studies of these systems. Long term time series of their variations obtainable using SCIMPI may prove critical to understanding their dynamics.

SCIMPI's comparatively low cost will enable time series measurements to become more commonplace, thereby improving our temporal and spatial knowledge of sub-seafloor gas, fluid, and pore pressure activity. Most notable among potential deployment targets for SCIMPI are sites with subseafloor gas hydrate and those with biogenic methane. Understanding the dynamics of methane's role in the oceans as climate change proceeds will contribute to a better understanding of the earth's carbon budget.

\section{Highlights}

- SCIMPI is a new borehole observatory designed to record physical properties time series.

- The first prototype is able to measure temperature, electrical resistivity and pressure.
- SCIMPI can run on batteries that require refreshment after two years, or it can be powered from a cabled network to provide real-time measurements.

- SCIMPI is ideal for studies of dynamic environments such as gas hydrates

Acknowledgements. SCIMPI is a collaborative effort funded by IODP-MI and led by the University of Rhode Island with major contributions from Transcend Engineering and Technology LLC and Woods Hole Marine Systems Inc. (WHMSI). Stress Engineering and Lamont Doherty Earth Observatories (LDEO) provided technical input and the deployment equipment. The authors would like to thank the R/V Endeavor, D/V JOIDES Resolution and R/V Thompson crew, technical support and expedition participants involved in this project. We are also thankful to Tori Kulin and Lucy Hurlbut for their support during the development of this project. Tania Lado-Insua was funded during this project by Fundación Pedro Barrié de La Maza, NSF and IODP-MI.

\section{Edited by: G. Camoin}

Reviewed by: K. Becker

\section{References}

Beerling, D., Berner, R. A., MacKenzie, F. T., Harfoot, M. B., and Pile, J. A.: Methane and the $\mathrm{CH}_{4}$-related greenhouse effect over the past 400 million years, Science, 309, 97-113, 2009.

Gorman, A. R. and Senger, K.: Defining the updip extent of the gas hydrate stability zone on continental margins with low geothermal gradients, J. Geophys. Res.-Sol. Ea., 115, B07105, doi:10.1029/2009JB006680, 2010.

Kitidis, V., Upstill-Goddard, R. C., and Anderson, L. G.: Methane and nitrous oxide in surface water along the North-West Passage, Arctic Ocean, Mar. Chem., 121, 80-86, 2010.

Kvenvolden, K. A.: A review of the geochemistry of methane in natural gas hydrate, Org. Geochem., 23, 997-1008, 1995.

Lado-Insua, T., Moran, K., Kulin, I., Farrington, S., Newman, J. B., and Morgan, S.: A multivariate approach to optimize subseafloor observatory designs, AGU Fall meeting 2012, San Francisco, USA, 2012.

Wenner, F.: A method of measuring earth resistivity, Washington, DC, US Department of Commerce, Bureau of Standards, Scientific papers of the Bureau of Standards, no. 258, 1916. 